\title{
Discussion about the Integration of Modern Information Technique and Athletics Teaching
}

\author{
LIUChuan-qin ${ }^{1}$, ZhanGyou-Ming ${ }^{2}$ and Wang-Ning3 \\ Institute of sports science, Mudanjiang Normal College, Mudanjiang, Heilongjiang, China
}

\begin{abstract}
Through documentary and logical analysis, the current integration of the outstanding problems of the modern information technology and physical education are analyzed, and on this basis to explore through the integration of modern information technology and physical education teaching to deepen teaching reform, optimize the structure of teaching, stimulate students interest in learning, better teaching results have been achieved.
\end{abstract}

Key words - Information technique, The athletics course, Integration

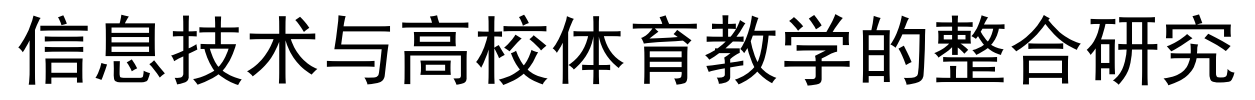

刘传勤 ${ }^{1} \quad$ 张有明 $^{2}$ 王宁 $^{3}$

牡丹江师范学院体育科学学院, 牡丹江, 黑龙江, 中国

\begin{abstract}
摘 要 通过文献资料法和逻辑分析法, 对目前现代信息技术与体育教学整合的突出问题进行了分析,并在此基础上探索通过现代 信息技术与体育教学的整合来深化体育教学改革,优化教学结构,激发学生学习兴趣,取得了较好的教学效果。
\end{abstract}

关键词 现代信息技术;体育教学:整合

伴随着信息时代的来临，教育信息化潮流势不可 挡，信息技术与高校体育课程有效整合是体育教学发 展的必然趋势。信息技术与体育课程整合是体育教师 在课程教学中超越不同知识体系，把信息技术、信息 资源、信息方法、人力资源和体育课程内容有机结合 的一种新兴教学方法。信息技术与体育课程有效整合 是体育课程教学的理想模式, 是现代高校体育课程教 学努力的方向, 但是, 如何更有效实施现代信息技术 与体育教学的整合还需要我们坚持不解地努力探索和 研究。

\section{1. 当前信息技术与高校体育课程整合的主要问题}

\section{1 硬件方面}

如果要将现代信息技术融入到体育教学中去, 必须要 有一定的信息技术资源做保障, 为体育课程整合提供坚实 的物质基础。如果没有足够的, 能够满足体育教学改革需 要的多样化、丰富化、社会化要求的教学内容和资源, 以 及适应当今现代社会信息化发展需要的网络资源, 信息技
术在体育教学改革中就无法得到很好的普及及应用。虽然 各大高校网络资源方面都已经普及, 但却没能在体育教学 改革中得到很好的利用, 这是其一; 同时当前教学资源不 管从内容上还是形式上, 在众多人的努力之下都有所改进, 但却仍难以适应新课程改革下的步伐, 很大程度上都不能 够满足体育教学改革大形势下的需要。

\section{2 软件方面}

现代信息技术的介入, 对广大高校体育教师都提出了 更高的要求, 暂时还只有一少部分人才能适用这些设备。 目前国内一些重点院校都已经配备了现代化的教学设备, 这其中包括计算机、数据库、网络、通信、微电子、图像 处理、视频抓拍、仿真等技术的设备，但大多数的教员在 短时间内还难以掌握这些高科技的教学工具, 甚至在某种 程度上不习惯, 甚至有排斥心理。其次, 老师的创新能力 有待提升。体育教学改革的大背景下, 对学生的体育创新 能力提出了很高的有求, 而提升该项指标的一个必备前提 是体育教学老师创新能力的提升。新时期, 教师不仅要具 
备传道授业解惑的能力, 更重要的是根据时代发展的需要 来充分掌握传道授业解惑的新工具、新手段和新途径。

\section{2. 现代信息技术与体育课程整合可行性建议}

\section{1 构筑体育信息资源平台}

构筑体育信息资源平台是为了促进知识更新, 并借助 网络信息资源来推进体育健身意识的传播, 所以构筑我国 体育资源共享平台, 是推行体育教学改革的大载体和实现 体育教学改革目标的必然途径。

\section{2 共享国内、国际体育信息}

目前一些相关学科的重大发现和发展以及高科技成果 在体育领域的应用使一些传统的体育科研方法和技术手段 被更新, 并打破了一些传统的概念和理论。如果不能及时 抓住体育科学领域内丰富的、有价值的信息, 及时更新陈 旧的知识并传授给学生, 那么就无从实现教育者自身素质 的提高和培养跨世纪的体育人才。而国内外各大不同特色 和类别的网站都能为我们提供大量有价值的信息, 通过网 络来搜寻这些信息能够大大减少我们的成本, 并能够迅速 地让我们掌握国际上体育界的动态和迅速地改变自身的技 能。作为一名体育工作者应该树立现代体育信息意识, 充 分掌握网络信息获取技能, 学会共享全球体育信息资源。

\section{3 利用网络资源来进行远程教育}

随着计算机网络技术的发展、高校计算机的普及和社 会对高等继续教育的需要, 网络远程教育将成为高校教育 改革的趋势和方向。高校体育教育应充分发挥自身的优势, 运用现代教育技术和网络技术促进教学改革, 以适应社会 发展的要求。通过网络远程教育推动实现继续教育, 高校 体育教学应充分利用自身优势, 通过制作网上教学课件, 提供网上教学资源, 推动网络远程体育教育向前发展。同 时针对网上体育教学资源的匮之, 应在共享网络体育信息 资源的同时, 结合专业知识和现代教育技术, 创造网上体 育教学资源。

\section{4 增强老师和学生的体育意识}

体育教学要想得到学生的配合并收到良好的结果, 首 先需要解决学生意识上的问题。所以学校领导要给予体育 教学以一个十分重要的位置, 同时要利用先进的网络资源 来为学生提供便捷和切实的服务, 反复地加强学生的体育 意识。

\section{5 体育教学系统化、科学化}

利用现代信息技术对学生的成长和发展能够起到科学 性的帮助。可以有针对性地对学生的优势和劣势进行攻关 训练。比如在学生进校时可以对每个学生都建立一个大学 期间四年的体育电子档案, 将学生的身体素质和体育技能 拆分成多个不同的考核指标, 改变以往光看考试成绩来决 定学生的优秀与否, 重视学生的进步和成长, 强化循序渐 进, 每天进步的意识。针对体育特长生可建立专业档案来 进行衡量, 针对普通生可建立合适体育发展指标体系来观 察其体育素质的变化。

\section{6 提高教师的体育素养}

“教改问题, 主要是教员问题”, 教师对现代信息技术的 把握水平是阻碍现代信息技术在体育教学中应用的一个很 重要的问题。所以提升教师信息技术素养势在必行, 这是 信息技术在体育课程应用过程中的必然要求。首先, 要提 高教师体育信息素质。体育信息素质是指对体育信息和信 息工作的认识深度和水平, 对大量体育信息资源的了解、 熟悉程度, 对获取、查询、检索、加工体育信息方法、手 段、技能的掌握情况。作为一名优秀的体育教师, 应该能 够篎分出一些需要的体育信息, 对信息应该具有敏感度, 随时了解国内、国际上的一些体育项目已经发展到了怎样 的水平, 以及时调整自己的教学内容、形式和手段。其次, 要提升教师对技术设备的掌握程度。现代信息技术能否成 为体育教学的重要教学手段, 取决于体育教师对现代信息 技术的掌握程度。所以要加强体育教师对现代信息技术手 段的培养, 教师不仅仅要掌握软件, 同时还需要对硬件设 施有很好的了解和掌握。

\section{3. 结束语}

信息技术与体育课程的有效整合会使体育教学内容与 教法发生一场深刻改革, 它鼓励采用以学生为中心的教学 方法, 充分调动学生学习与锻炼的自主性和积极性。信息 技术教学是通过一定的技术平台实现多方向的知识信息传 递, 通过师生之间、学生之间的互动学习来实现一种新的 分享式的学习模式, 便于更快捷地促进个体间的交流, 为 新教学模式的营造以及新学习团队的形成提供极为有用的 技术支持。信息技术与体育课程有效整合是理想化的教学 模式, 在体育教学实践中, 还要根据不同的教学内容、方 法、环境及要求灵活运用信息技术, 使信息技术在体育教 学中的作用最大化, 在强调信息技术教学重要性的同时, 也要避免矫枉过正, 违背体育教学规律, 忽略体育课程的 主要特征, 使体育课程变成纸上谈兵的课程教学。 


\section{参考文献(References)}

[1] Wuhengye. The exploration of modern information technology and physical education integration Journal of jilin institute of physical education, 2005.

[2] Lliqing Research on network information technology application in physical education teaching journal of Xiangtan normal university 2005(7): 165-166.
[3] Yaoguoxiang. The exploration of Information technology and university curriculum integration Higher Education Exploration, 2005(1): 71

[4] Wang lehua, hanqi. From the perspective of modern curriculum theory the ordinary university sports curriculum objectives and content. Journal of nanjing institute of sport (social science edition) 2008(02): 95-97 